\title{
EXERCISE-ASSOCIATED SELF-EFFICACY AND BEHAVIORAL CHANGES AND THEIR IMPACT ON HEALTH-RELATED QUALITY OF LIFE OF MIDDLE-AGED WOMEN OF KLANG VALLEY, MALAYSIA
}

\section{HAFIZAH CHE HASSAN ${ }^{1 *}$, PALLAV SENGUPTA ${ }^{2}$}

${ }^{1}$ Dean, Faculty of Nursing, Lincoln University College, Petaling Jaya, Selangor Darul Ehsan, Malaysia, ${ }^{2}$ Head, Physiology Unit, Faculty of Medicine, Lincoln University College, Petaling Jaya, Selangor Darul Ehsan, Malaysia. Email: hafizahche@lincoln.edu.my

\author{
Received: 09 May 2017, Revised and Accepted: 30 May 2017
}

\section{ABSTRACT}

Objectives: This study aims to elucidate the impacts of self-efficacy and behavioral changes on exercise that may affect health-related quality of life (HRQoL) of middle-aged Malaysian women.

Methods: A questionnaire-based data collection was performed from October 2013 to March 2014 in the Klang Valley, Malaysia. SPSS (v. 21.0 ) was used to analyze the data after recording body mass index, general health, physical health status, self-efficacy and self-awareness associated to HRQoL. Correlation between the parameters was calculated using Pearson's correlation coefficients, and the reliability test was conducted using Cronbach's alpha $(\alpha)$. Results are mentioned as significant when $P$ values are found to be $<0.05$.

Results: Findings of the study indicated, though women of Klang Valley suffer from few health problems, they prefer exercise to maintain their HRQoL. It has been observed that self-efficacy and behavioral changes for exercise related quality of life are affected by several factors, such as education, monthly income, marital status, and even ethnicity.

Conclusions: This study portrays that women of Klang Valley, Malaysia, are inflicted with quite a good self-efficacy to exercise, which impacts their HRQoL.

Keywords: Behavioral changes, Body mass index, Health, Quality of life, Self-efficacy.

(C) 2017 The Authors. Published by Innovare Academic Sciences Pvt Ltd. This is an open access article under the CC BY license (http://creativecommons. org/licenses/by/4. 0/) DOI: http://dx.doi.org/10.22159/ajpcr.2017.v10i9.19818

\section{INTRODUCTION}

At the $57^{\text {th }}$ World Health Assembly, the World Health Organization (WHO) endorsed the Global Strategy "to improve public health through healthy eating and physical activity" through Diet, Physical Activity and Health Survey for 2005-2007 [1]. This echoes recognition from international sectors of the worldwide changes in physical activity levels and dietary habits as a consequence of countries' development demographic and socioeconomic arena, and globalization. Better health care has leads to longer life expectancy together with the addition of declining fertility rate has resulted in the increase of the proportion of the elderly population in most countries in the world $[2,3]$. The WHO has also reported that by 2050 there will be 2 billion elderly women in the world and majority of them will be from developing countries [2]. According to the department of statistics, Malaysia (2010) the ageing population of 60 years and above had increased steadily from $5.7 \%$ in 1990 to $6.3 \%$ in 2000 and is expected to raise further to $9.8 \%$ in 2020 and it is projected that by $2025,13.3 \%$ of Malaysia's population will comprise elderly. Like other countries, upturn in aged population in Malaysia is resulted from improvements in the health system causing declining fertility and falling mortality rates [4].

According to Broome, as compared to men, women in developed countries experience more disease, but they outlive men [5]. This entails that many older women live with the consequences of several diseases, like coronary heart diseases (CHDs) which account for one-third of all deaths among women worldwide [6]. This entails that despite religious and cultural variations they enjoyed better life as compared to other women in terms of health status, less conflict and free from natural adversities.

Since women who adopt healthier lifestyles are likely to live longer, it is essential to find out the ways to implement the WHO strategies to improve the quality of life (QoL) among elderly women [7]. Achieving QoL through self-efficacy and behavioral changes have been a critical and quite impartial in the larger sense, to the concept in health and the world of health care. Thus, this research aims to know how Malaysian women approach their health in middle age, and the contributing factors are making positive health behavior changes in woman.

\section{METHODS}

\section{Study region}

This study was conducted in Klang Valley, which is centered in Kuala Lumpur, the capital of Malaysia and includes its adjoining cities and towns in the state of Selangor. It is situated in the western part of peninsular Malaya. It comprises 40 districts (Fig. 1) and a population of about 7.2 million or more than a fifth of Malaysian population [3].

\section{Study population and sample size}

It is an essential part of the research to determine the sample size. Inadequate or excessive sample size contributes to influence the quality and accuracy of research analysis [8,9]. To get a true presentation of the target group, the sample size was determined using the formula of Kadir [10]. The study was taken as an estimation for initial rate $(P)$ in calculation for the sample $(N)$. The study indicated from the QoL in the older women $60 \%$ as this study focus on middle age women in Malaysia.

$$
N=\frac{U^{2} P Q}{E^{2}}
$$

$$
N=\frac{(1.96)^{2}(57)(43)}{5^{2}}=377
$$




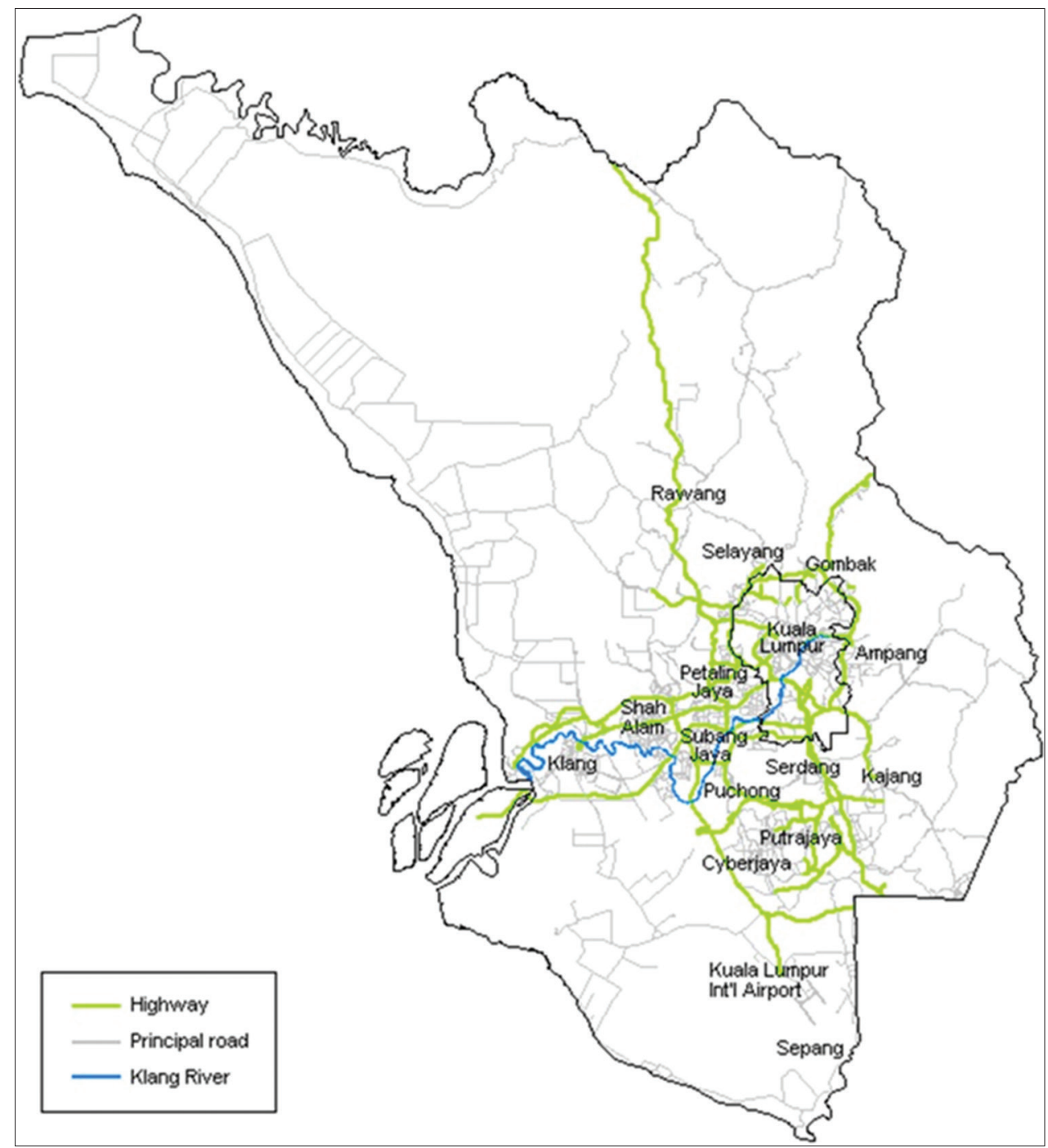

Fig. 1: Klang Valley - the study region

According to the calculation, the minimum sample size for the study should be 377 subjects, but the sample size was increased to represent the population and finalized to 736 subjects. Subject inclusion criteria were: Middle-aged women (40-65 years of age), original Malaysians and who are able to understand English language. Whereas, subjects with age of $<40$ or more than 65 -year-old, foreigners, and non-English speakers were excluded from the study.

\section{Data collection}

A total of 1000 questionnaires were provided to the women of 40 districts in Klang Valley during September-October 2013. For convenience sampling was done in batches returned questionnaires were checked by a research assistant to ensure their completion.

Information regarding completed questionnaires was recorded by either the research assistant or the researcher using a coding system to identify the name of the mid-aged women who had completed the questionnaire. Information such as new forwarding addresses, notification that the participant was on overseas, or advice that previous participants did not want to continue to be involved in the study was also recorded. Out of the 1000 women who the questionnaires were mailed, a total of 736 questionnaires completed and returned.

There were a total of 17 questions designed to evaluate for healthrelated QoL (HRQoL): Six questions for demographic data, 10 healthrelated questions and one question for QoL. The questionnaire was taken from SF36 from the pilot study was conducted, and its Cronbach's alpha for the 8 dimension is more than 0.70 .

\section{Ethical consideration}

The study was approved by the Research Ethic Committees Lincoln University College. Consent from the respondents was taken when they are answering the questionnaire.

\section{Sociodemographic data}

These questions include age, weight, height, marital status, race, qualification, employment, and monthly household income of the subjects. These data were collected to identify whether any of the sociodemographic variables might influence variables such as self-efficacy and HRQoL.

\section{Body mass index}

Self-report about their height and weight were used for the calculation of body mass index (BMI). This was calculated by dividing the weight in kilograms by the square of the height in meters $\left(\mathrm{kg} / \mathrm{m}^{2}\right)$. The BMI categories used were those developed by the WHO, 2006 [11]. As with sociodemographic data, data for the calculation of BMI were included to determine whether BMI might be related to the key variables and need to be analysis with other variables.

\section{General health}

Some questions of the survey questionnaire referred to "general" in Likert scale excellent, very good, good, fair, and poor, while other 
questions are regarding women health that includes hysterectomy, removal of ovaries, menstrual period, the duration of cessation of menstrual period, and finally the female hormone.

\section{Physical health status}

There are 14 items in question 6 of HRQoL which were "Yes" and "No" answer. Participants were provided with a list of health conditions and asked to indicate whether they previously or recently had been diagnosed with any of them. The list included: Headaches/migraine, stroke, high blood pressure, back problem, CHD, other heart diseases, irritable bowel problem, thyroid disorders, arthritis and rheumatism, diabetes, breast cancer, cancer (any other type), osteoporosis, and mental health problems.

\section{Health perception and health awareness}

Question 8 measured the perception of the participants'. Participants were asked how they perceive in general and how they rate their health status compared to last year and strategies in improving one's health. Question 9 consisted of "Yes" and "No" answers, participants were asked to perceive their health awareness regarding checking themselves for Pap smear, breast check by health professional, and breast self-examination.

\section{Health self-efficacy and quality of life}

In the survey questionnaire, question 10 was designed to assess health self-efficacy. Participants were asked how they determined their health improving. Less determination is presented as low selfefficacy, moderate determination as moderate self-efficacy and very determined for high self-efficacy in health. These questions consisted exercise, medical check-up, alternative treatment, eating healthy food and stress control. Overall, QoL consisted only one question, where the participants rate their QoL in the Likert scale from excellent to poor.

\section{Data analysis}

Data analysis was performed using Statistical Package for Social Science 21.0 (SPSS Inc., Chicago, USA). Calculation of Pearson's correlation coefficients was implied to check the hypothesis. Results are mentioned as significant when $\mathrm{P}$ values are found to be $<0.05$. The reliability test was conducted using Cronbach's alpha $(\alpha)$ to ensure that the reliability of the items used was achieved in this study [12]. This test measured the consistency of the items (whether the sample answers on all items were consistent or not). It is the most widely used measure for assessing internal consistency reliability and its value above 0.7 is acceptable, and above 0.8 is preferable for analysis. The value of alpha usually ranges from 0 to 1 . Values of Cronbach's alpha are between 0 (very low consistency) and 1 (very high consistency). To be a good measure of reliability and in such a case, the results can be generalized. Hair et al. (2010) proposed four different levels of reliability an excellent level ( 0.90 and above), a high level (from 0.70 to 0.90 ), a high moderate level (between 0.50 and 0.70 ), and a low level (0.50 and below) [12].

\section{RESULTS}

\section{Sociodemographics of respondents}

A total of 736 respondents completed and replied the questionnaire. Table 1 summaries the data pertaining to respondents' information. The data show respondents' age, marital status education, race, employment status, and monthly income. It also shows that majority of the female $(50.3 \%)$ fall in the age group of $40-49$ years old, followed by $50-59$ years $(34.1 \%)$ and $60-69$ years $(15.6 \%)$. In terms of marital status of the participants, $59 \%$ were married followed by separated $(22.6 \%)$ while the number for single and never married was least (18.5\%).

The occupational qualification of the participants revealed that majority of the participants (40.1\%) had a degree from university while $22 \%$ had attained college qualification, technical certificate or diploma, and $13.6 \%$ had completed primary school. The percentage of participants who had completed lower certificate of education (SRP) was $8.1 \%$.
Majority of the participants were Malays (41.3\%), followed by Chinese (34.4\%), Indian $(20.2 \%)$, and others (4.1\%). The income status of the participant showed that majority (34.9\%) had an income of $<3000$ MYR, followed by 5001-8000 MYR (26.2\%), more than 10,001 MYR (17.9\%), and the least income 3001-5000 MYR were received by (8.6\%) participant.

\section{Body mass index}

Out of the 736 middle-aged women respondents, and 636 were having normal BMI (86.4\%) whereas underweight was $4.1 \%$ and for overweight was only $9.5 \%$ (Table 2 ).

\section{Self-efficacy on exercise}

Table 3 reflects self-efficacy for exercise. It is divided into two categories comprises low and high category. High category showed that there was an increase in self-efficacy for exercise (50.3\%) than low category (42.3\%).

\section{Health behavior}

The analysis of health behavior change of exercise was performed pertaining to types of exercise and deliberate changes were made by respondents. Frequencies of exercise were analyzed.

\section{Types of exercise}

The data analysis in Table 4 was based on 12 types of exercise and sports. The sports or exercise higher practiced by middle-aged women

Table 1: Sociodemographics of respondents $(n=736)$

\begin{tabular}{ll}
\hline Demographics & Frequency (\%) \\
\hline Age (years) & \\
$40-49$ & $370(50.3)$ \\
$50-59$ & $251(34.1)$ \\
$60-69$ & $115(15.6)$ \\
Marital status & \\
Married & $434(59.0)$ \\
Separated & $166(22.6)$ \\
Single/never married & $136(18.5)$ \\
Educational qualifications of the respondents & \\
Completed primary school & $100(13.6)$ \\
SRP & $59(8.0)$ \\
Malaysian certificate (SPM) & $120(16.3)$ \\
Trade, technical, certificate, or diploma & $162(22.0)$ \\
University or college degree & $295(40.1)$ \\
Ethnicity of the respondents & \\
Malay & $304(41.3)$ \\
Indian & $149(20.2)$ \\
Chinese & $253(34.4)$ \\
Others & $30(4.1)$ \\
Monthly income (RM) & \\
<3000 & $257(34.9)$ \\
3001-5000 & $63(8.6)$ \\
5001-8000 & $193(26.2)$ \\
8001-10,000 10,001 & $91(12.4)$ \\
\hline & $132(17.9)$ \\
\hline
\end{tabular}

Table 2: Body mass index status of respondents

\begin{tabular}{ll}
\hline BMI & Frequency (\%) \\
\hline Underweight & $30(4.1)$ \\
Normal & $636(86.4)$ \\
Overweight & $70(9.5)$ \\
Total & $736(100.0)$ \\
\hline
\end{tabular}

BMI: Body mass index

Table 3: Self-efficacy on exercise and diet

\begin{tabular}{llll}
\hline Self-efficacy & Mean & Low (\%) & High (\%) \\
\hline Exercise & 2.96 & 42.8 & 50.3 \\
& & 57.7 & 42.3 \\
\hline
\end{tabular}


Table 4: Types of on exercise

\begin{tabular}{|c|c|c|c|c|c|c|}
\hline S. No. & What sport or exercise did you do most frequently & Means & Not at all & Low & Moderate & High \\
\hline \multirow[t]{2}{*}{1} & Walking & 2.95 & 232 & 60 & 98 & 344 \\
\hline & & & 31.5 & 8.2 & 13.3 & 46.7 \\
\hline \multirow[t]{2}{*}{2} & Aerobic & 2.70 & 263 & 80 & 77 & 316 \\
\hline & & & 35.7 & 10.9 & 10.5 & 42.9 \\
\hline \multirow[t]{2}{*}{3} & Gardening & 2.54 & 327 & 42 & 88 & 279 \\
\hline & & & 44.4 & 5.7 & 12 & 37.9 \\
\hline \multirow[t]{2}{*}{4} & Jogging & 2.39 & 389 & 44 & 34 & 269 \\
\hline & & & 52.9 & 6 & 4.6 & 36.6 \\
\hline \multirow[t]{2}{*}{5} & Dancing & 2.36 & 376 & 47 & 65 & 248 \\
\hline & & & 51.1 & 6.4 & 8.8 & 33.7 \\
\hline \multirow[t]{2}{*}{6} & Swimming & 2.08 & 458 & 13 & 42 & 223 \\
\hline & & & 62.2 & 1.8 & 5.7 & 30.3 \\
\hline \multirow[t]{2}{*}{7} & Bowling & 1.92 & 527 & 17 & 22 & 170 \\
\hline & & & 71.6 & 2.3 & 3 & 23.1 \\
\hline \multirow[t]{2}{*}{8} & Volleyball & 1.80 & 549 & 9 & 10 & 167 \\
\hline & & & 74.6 & 1.2 & 1.4 & 22.7 \\
\hline \multirow[t]{2}{*}{9} & Cycling & 1.58 & 603 & 6 & 23 & 104 \\
\hline & & & 81.9 & 0.8 & 3.1 & 14.1 \\
\hline \multirow[t]{2}{*}{10} & Table tennis & 1.41 & 629 & 30 & 10 & 64 \\
\hline & & & 85.5 & 4.1 & 1.4 & 8.7 \\
\hline \multirow[t]{2}{*}{11} & Golf & 1.38 & 643 & 9 & 13 & 71 \\
\hline & & & 87.4 & 1.2 & 1.8 & 9.6 \\
\hline \multirow[t]{2}{*}{12} & Tennis & 1.24 & 666 & 9 & 30 & 28 \\
\hline & & & 90.5 & 1.2 & 4.1 & 3.8 \\
\hline
\end{tabular}

was walking (46.7\%) and aerobic (42.9\%). The lowest was tennis and golf $(9.6 \%)$ and $(3.8 \%)$.

\section{Deliberate change to the exercise}

The respondents were enquired regarding their exercise pattern and frequency after age 40 . There is a deliberate change $(58.7 \%)$ and frequency of exercise among the middle-aged women.

Level of exercise after change after 40 years of age among middle age women

This data analysis in Fig. 2 reveals the changes in the level of exercise and the decrease or increase in the pattern by the respondents. Majority $(58.4 \%)$ showed small increase $(11 \%)$ showed a large increase in their exercise pattern. A moderate decrease (6.7\%) was seen among the women.

\section{DISCUSSION}

In general, the demographic data such as the BMI, age, marital status, education, income, and ethnicity of middle-aged women affect HRQoL. These demographics can be helpful in achieving a HRQoL $[13,14]$. As mentioned above, of the 736 middle-aged women respondents, 312 were having normal BMI (86.4\%), whereas underweight was $4.1 \%$ and for overweight was only $9.5 \%$. However, during the interview, it was observed and the data collected about $20.8 \%$ were found to obese. The Third National Health and Mobility Survey (NHMS III) was conducted on 2006 and found that $29.7 \%$ male and $28.6 \%$ female in the country are overweight, and very expectedly the percentage of female is more $(17.4 \%)$ of female (BMI $~ 30)$ compared to the male $(10.0 \%)$. But report in NHMS (2015) mentioned the prevalence of obesity is on the increasing trend, and it is about $17.7 \%$ ( $\sim 3.3$ million) adult above 18 years old. Obesity and overweight lead to other health problems including diabetes mellitus, cardiovascular diseases, hypertension, high blood cholesterol, cancer, and even mental illness [15]. Based on research from 1996 until 2006, the minister of health reported that the noncommunicable diseases (NCDs) showed a rapid increasing trend, like the cases of high blood pressure (44\%) and diabetes mellitus (80\%) [15]. The worst circumstance was the increase of obesity cases by $220 \%$ [16] in Malaysia, and until 2006, 29\% of adults were reported as overweight and $14 \%$ as obese.

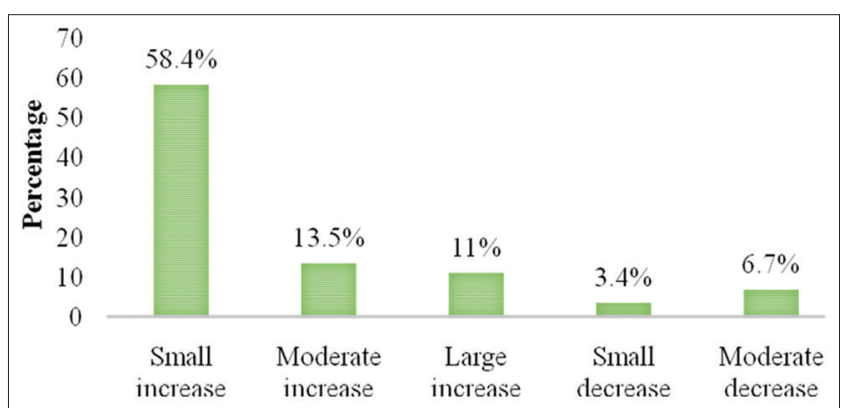

Fig. 2: Respondents' level of exercise after change

Two main factors those were identified during the interview describing the cause why the respondents want to increase their exercise behavior was: First, to improve their health status due to doctor advised, such as to reduce high cholesterol and/or to high blood pressure, second, to reduce their body fat and maintain a slim body and preventing themselves to become overweight or obese.

More than half (59\%) of the women were found to be married, $22.6 \%$ were divorced or separated and almost less than a quarter (18.5\%) were single or never married. Marital status also found to affect the health self-efficacy of middle-aged women. Married women are mostly focused on their children and family which makes them ignorant about their own health and were found to put limited effort on their health concerns. This goes along with Bandura's (1977) assertion that "performance or mastery experiences, role models, support from others, and the participants' own self-appraisal which affect selfefficacy due marital status" [17].

Out of 736 respondents, $37.1 \%(\mathrm{n}=273)$ have high blood pressure, followed by $23.8 \%(\mathrm{n}=175)$ with headache/migraine, and $16.7 \%$ $(n=123)$ with leaking urine when coughing and sneezing. This means that migraine and high blood pressure and stress incontinence can affect the health self-efficacy of middle-aged women in Klang Valley. Supporting literature also claims that diabetes can lead to high blood pressure [3]. The fourth problem that impacts on middle-aged women in Klang Valley are back problem ( $\mathrm{n}=105$ or $14.3 \%$ of respondents) that also found to affect their general health. This suggests that health 
self-efficacy is affected by health problems. Physical immobility such as back problems is one of the leading contributors to preventable illness and, thus, mobility is conceded $[18,19]$. Baumann et al. also reported that majority of the participants with back problems will eventually lead to obesity and can be observed through BMI, and the domain of health self-efficacy will affect the HRQoL. The data also showed that increase in age also causes increased health problems.

The findings suggest that respondents with monthly household income below MYR 3,000 have a lower HRQoL compared to middle-aged women who lived in a household income with more than MYR 5001. Income for the two age groups reflected the disparity in employment. The group with monthly income of MYR 5001 or above was nearly twice as likely to earn at the lowest level (12.6\%). This suggests that the HRQoL is achieved by health self-efficacy that is influenced by monthly income of the family. It is definite that the more the income of middle-aged women, more chances to have health checkups. More concern on women's health also requires more payment to insurance company.

In this study, the ethnicity group that was involved Malay, Chinese, Indian, and others. The HRQoL showed that the Chinese having the lowest for all dimensions among all ethnic groups. It is also found that Chinese score the lowest mean difference among groups. Physical component summary (Mean=50.10, $\mathrm{p}=0.00$ ) and mental component system (mean $=41.26, \mathrm{p}=0.00$ ) for all dimensions' averages mean score for Chinese group around $40 \%$ lower than the Malays and Indians. Some recent studies on Malaysian diabetics revealed a wide variety in HRQoL among multi-ethnic, multiple languages spoken Asian population as found in Malaysia [20,21]. This study also reports Chinese scored less HRQoL than Malays and Indians. Teh et al., in their study regarding ethnic and gender differences in NCDs found that there was a significant interaction between ethnicity and disease [22]. Chinese respondents who were suffering from high blood pressure were more likely to report poor health compared to the Malays and Indians.

Out of 736 respondents, only 304 made a change in their exercise regime, and the level of change is about $58.4 \%$ had made small increase and followed by $41.3 \%$. Women with higher self-efficacy $(50.35 \%)$ made changes by taking up exercise to have a healthy lifestyle.

Thiele et al., [23] Boynton et al., [24] and Saavedra et al. [25] identified that education play a key role in relation to exercise. It was confirmed in this study that women with higher education levels were more likely to make a positive change to their exercise in midlife. Since education was also shown to be linked with BMI and exercise self-efficacy, it seems that women with the lower education levels are less likely to believe that they can eat healthily or exercise regularly, and they are more likely to be overweight or obese, compared to women with more education. The study suggested that when a woman is dealing with a range of variables that could impact self-efficacy (e.g., low education level, a high BMI, and poor mental health), it may be extremely difficult for her to adopt positive health behaviors.

Lee and Laffrey's contention that previous exercise experience was central to whether women exercised in older age was generally supported in this study [26]. Women who had been overweight during childhood tended to be overweight in their 50 seconds and 60 seconds, with low self-efficacy for exercise or diet mention by Lee and Laffrey's and also, they were also more likely to be impeded by work, care giving, stress, injury, illness, pain, and fear [26]. As Trudeau et al. and Conroy et al. suggested, being fit and active as a girl may be a factor in determining whether women seek to improve their exercise and diet in midlife $[27,28]$.

Schools provide an opportunity to expose girls to positive experiences of being active and to address the gendered views of girls and women's roles that prevent women from taking the best care of their health. In recent years, however, daily physical education has become a lower priority in schools in the face of pressure from parents for academic performance. The importance of physical education and an education in nutrition needs to be re-established in schools across all grades. Mothers' attitudes and behaviors also have a huge impact on girls, and a program for schools which involves both mothers and daughters could have considerable merit $[29,30]$.

Healthy lifestyle programs aimed at midlife women need to recognize that some women have not had previous experiences to provide them with the belief that they can be successful in exercising regularly or eating healthily. This would require a focus on the information sources identified by Bandura as being critical to the development of self-efficacy, such as helping women to develop those experiences in a supported environment, identifying credible role models, and encouraging positive self-appraisal [17].

\section{REFERENCES}

1. World Health Organization. Global Strategy on Diet, Physical Activity and Health; 2014. Available from: http://www.who.int/ dietphysicalactivity/strategy/eb11344/strategy.

2. World Health Organization. Review of Best Practice in Interventions to Promote Physical Activity in Developing Countries. Background Document Prepared for the WHO Workshop on Physical Activity and Public Health. Beijing: WHO Publishing; 2005.

3. World Health Organization. Active Ageing: A Policy Framework. Geneva: WHO; 2002.

4. Malaysia Department of Statistic. Population and Housing Census, Malaysia 2010 Census, Putrajaya; 2010.

5. Broome B. Women and health care. Urol Nurs 2007;27(2):81-3, 92.

6. Lockyer L, Bury M. The construction of a modern epidemic: The implications for women of the gendering of coronary heart disease. J Adv Nurs 2002;39(5):432-40.

7. Omar R. Being old in Malaysia: Issues and challenges of older women. Anthropol Soc Pap 2003;89(90):116-31.

8. Lenth RV. Some practical guideline for effective sample determination. Am Stat 2001;55:187-93

9. Hoeing JM, Heisey DM. The abuse of power: The pervasive fallacy of power calculation for data analysis. Am Stat 2001;55:19-21.

10. Kadir RA. [Panduan Kaedah Epidermiologi Pergigian (Methodology Guidance of Epidermiology)]. London: Dewan Bahasa Pustaka (In Malay Language); 1989. p. 25-7.

11. World Health Organization. Obesity and Overweight. Fact Sheet Number. 311; 2006. Available from: http://www.who.int/mediacentre/ factsheets/fs $311 /$ en.

12. Hair JF, Black WC, Balin BJ, Anderson RE. Multivariate Data Analysis. $7^{\text {th }}$ ed. Englewood Cliffs: Prentice Hall; 2010.

13. Sengupta P. A report on body composition and fitness status of young men of Toto community: An endangered tribe of India. Indian J Med Spec 2016;7(3):95-9

14. Sengupta P, Krajewska-Kulak E. Evaluation of physical fitness and weight status among fisherwomen in relation to their occupational workload. J Epidemiol Glob Health 2014;4(4):261-8.

15. National Health and Mobility Survey (NHMS III); 2015.

16. Gaya HB. Hiduppuncaramaiberpenyakit; 2012. Available from: http:// www.pmr.penerangan.gov.my/index.php/penafian/7085-html.

17. Bandura A. Self-efficacy: Toward a unifying theory of behavioral change. Psychol Rev 1977;84(2):191-215.

18. Bauman A, Bellew B, Vita P, Brown W, Owen N. Getting Australia active: Towards better practice for the promotion of physical activity. Melbourne, Australia: National Public Health Partnership; 2002.

19. Sengupta $P$. The bliss yoga inculcates during the different stages of pregnancy. Int J Pharm Pharm Sci 2014;6(10):86-7.

20. Daher AM, AlMashoor SA, Winn T. Glycaemic control and quality of life among ethnically diverse Malaysian diabetic patients. Qual Life Res 2015;24(4):951-8.

21. Goh SG, Rusli BN, Khalid BA. Diabetes quality of life perception in a multiethnic population. Qual Life Res 2015;24(7):1677-86.

22. Teh JK, Tey NP, Ng ST. Ethnic and gender differentials in noncommunicable diseases and self-rated health in Malaysia. PLoS One 2014;9(3):e91328.

23. Thiele S, Mensink GB, Beitz R. Determinants of diet quality. Public Health Nutr 2004;7(1):29-37

24. Boynton A, Neuhouser ML, Sorensen B, McTiernan A, Ulrich CM. 
Predictors of diet quality among overweight and obese postmenopausal women. J Am Diet Assoc 2008;108(1):125-30.

25. Saavedra JM, Torres S, Caro B, Escalante Y, De la Cruz E, Durán MJ, et al. Relationship between health-related fitness and educational and income levels in Spanish women. Public Health 2008;122(8):794-800.

26. Lee YS, Laffrey SC. Predictors of physical activity in older adults with borderline hypertension. Nurs Res 2006;55(2):110-20.

27. Trudeau F, Laurencelle L, Tremblay J, Rajic M, Shephard RJ. Daily primary school physical education: Effects on physical activity during adult life. Med Sci Sports Exerc 1999;31(1):111-7.

28. Conroy MB, Cook NR, Manson JE, Buring JE, Lee IM. Past physical activity, current physical activity, and risk of coronary heart disease. Med Sci Sports Exerc 2005;37(8):1251-6.

29. Chaudhuri P, Bhattacharya K, Sengupta P. Misty role of amygdala in female reproductive behavior. Int J Pharm Pharm Sci 2014;6(2):563-4

30. Sengupta P. A small-scale cross-sectional study for the assessment of cardiorespiratory fitness in relation to body composition and morphometric characters in fishermen of Araku valley, Andhra Pradesh, India. Int J Prev Med 2014;5(5):557-62. 